\title{
Pesca esportiva e pesca artesanal: lazer e sobrevivência na Hidrelétrica de Tucuruí (PA) ${ }^{1}$
}

\section{Sport fishing and artisanal fishing: Leisure and subsistence at the Tucuruí (PA, Brazil) hydroelectric power plant}

Cleide Lima de Souza, Voyner Ravena Cañete

\section{RESUMO}

Este artigo descreve o cenário que envolve a pesca e suas nuances no lago artificial da hidrelétrica de Tucuruí-Pa (Brasil). Enfatiza as contradições no acesso e uso dos recursos pesqueiros que permeiam realidades bastante antagônicas: um grupo que realiza a pesca esportiva por diversão e lazer e outro de pescadores artesanais que busca o sustento nesta atividade, principal fonte de renda e de alimento. Os procedimentos metodológicos primaram pela investigação junto aos pescadores no interior do lago por meio de trabalho de campo e compilação de dados secundários em três municípios que detêm a maior produção de pesca (Tucuruí, Nova Jacundá e Novo Repartimento) dos sete que envolvem o lago. Tece análise a partir das políticas de ecoturismo, da pesca esportiva e da pesca artesanal. Utiliza-se da categoria memória coletiva para descrever o ambiente aquático anterior ao lago e compreender de que forma esta memória contribui para os pescadores locais e os imigrantes no processo de adaptação e criação de novas práticas para acesso e uso dos recursos pesqueiros. $\mathrm{O}$ artigo conclui que a pesca esportiva, concebida como uma atividade de ecoturismo desenvolvida em um ambiente fortemente impactado impõe uma nova dinâmica aos pescadores artesanais, demandando dos mesmos a informação sobre a localização dos pontos de pesca e a geografia do lago. Por outro lado, o pescador artesanal passa a se relacionar com a sociedade maior através do seu saber, estabelecendo uma relação com o mercado mediada por um novo produto: o saber sobre a própria atividade da pesca.

PALAVRAS-CHAVE: Lago Artificial; Pesca Esportiva; Pesca Artesanal; Memória Coletiva; Ecoturismo. 


\begin{abstract}
This article describes the context related to fishing and its nuances at the artificial lake at the hydroelectric power plant of Tucuruí (PA, Brazil). The article emphasizes the contradictions in the access and use of fishing resources of quite antagonistic realities: a group involved in sport fishing for recreation and leisure and another group of artisanal fishermen that carry out the activity as their main form of subsistence, source of income and food supply. The methodological procedures focused mainly on an investigation with lake fishermen by means of a fieldwork and the compilation of secondary data in 3 of the 7 municipalities that sorround the lake. The municipalities of Tucuruí, Nova Jacundá and Novo Repartimento present the major fishing production in the area. The article also develops and analysis based on ecotourism policies, sport fishing and artisanal fishing. The category collective memory is used to describe the aquatic environment before the creation of the lake and understand how this form of memory contributes to local fishermen and immigrants in the process of adaptation and creation of new practices for the access and use of fishing resources. The study concludes that sport fishing, conceived as an ecotourism activity developed in an environment that is greatly impacted imposes a new dynamic to artisanal fishermen, demanding from them the information about the localization of the fishing spots and the geography of the lake. On the other hand, artisanal fishermen develop a form of relationship with society through its knowledge, establishing a relation with the market mediated by a new product: the knowledge about the fishing activity itself..
\end{abstract}

KEYWORDS: Artificial Lake; Sport Fishing; Artisanal Fishing; Collective Memory; Ecotourism.

\title{
Introdução
}

As mudanças decorrentes do processo globalizante transformaram a relação sociedade e natureza. A partir da década de 1970, movimentos ambientalistas passaram a defender o modelo de desenvolvimento sustentável com intuito de garantir a conservação dos recursos naturais. A implantação de parques ambientais com vista às práticas de contemplação da natureza emerge como uma forma de preservação e, ao mesmo tempo, alternativa econômica, à medida que se presta um serviço, estabelecido, assim, nas políticas públicas de lazer com enfoque ecológico (COELHO, 1999).

Vale ressaltar que a percepção da possibilidade de escassez dos recursos naturais, até então concebidos como fonte inesgotável, passou a sinalizar limites resultantes do impacto causado pelo crescimento industrial e populacional. É nesse cenário que as teorias preservacionistas e conservacionistas emergem nos Estados Unidos promovendo a expansão do modelo de criação de Parques, com a finalidade de inibir a ação humana (DIEGUES, 2001, 2000), o que, ainda hoje, provoca muitas discussões a respeito da relação sociedade e natureza.

Dentro desse campo surge o ecoturismo². Todavia, Castro (1999) assegura que avanços da economia e da sociedade moderna se ancoraram 
na exploração de novas fronteiras dos recursos naturais e de novos territórios, de modo que a estratégia de gestão socioambiental desses recursos representa indícios da apropriação da natureza pelo capital. Nesse contexto, se concebe a atividade do ecoturismo como uma prática de desenvolvimento sustentável. Sua conceituação, atribuída pelo Ministério do Turismo através da diretriz nacional do ecoturismo, assim se define:

Ecoturismo é uma atividade do segmento turístico que utiliza, de forma sustentável, o patrimônio natural e cultural, incentiva sua conservação e busca a formação de uma consciência ambientalista por meio da interpretação do meio ambiente, promovendo 0 bem-estar das populações (MINISTÉRIO DO TURISMO, 2010, p.11).

Como se observa, o próprio conceito envolve uma multiplicidade de práticas para sua consolidação. Dentre elas, a formação de uma consciência ambiental, o que deveria preceder a atividade turística (FIGUEIREDO, 1999). Por considerar a importância do ecoturismo uma alternativa de desenvolvimento sustentável, bem como provedor de benefícios sociais e ambientais para o país, foi criada a Portaria no 001, de 20 de abril de 1994, que instituiu o grupo Interministerial para desenvolver e propor Diretrizes para uma Política Nacional de Ecoturismo. O grupo foi composto por integrantes do Instituto Brasileiro do Meio Ambiente e dos Recursos Naturais Renováveis, do Instituto Brasileiro de Turismo, do Ministério da Indústria, do Comércio, do Turismo e do Meio Ambiente além de diversas Organizações não Governamentais.

O documento expressa o reconhecimento mundial sobre a biodiversidade brasileira e o êxito no ecoturismo presente em outros países, enfatizando que, mediante as riquezas naturais do Brasil, o mesmo se tornaria viável. No entanto, menciona condições de difícil alcance, como infraestrutura, capacitação, conscientização, dentre outras questões que são de complexa solução e que podem se agravar à medida que se difunde a informação sobre os recursos naturais, sobretudo, por envolver lucro.

De acordo com as diretrizes da política nacional de ecoturismo, sua implantação incide diretamente na possibilidade de melhoria da qualidade de vida das populações locais e na valorização dos recursos naturais assim como na visibilidade internacional da beleza natural e cultural existente no Brasil. Ressalta-se que a efetividade dessa política se daria na parceria público/privado, incluindo a população local como principal beneficiada da política com melhorias na condição de vida, conservação e valorização dos recursos naturais.

Nessa proposta, a região amazônica ganha destaque pela sua dimensão ambiental por possuir uma vasta floresta marcada pela presença de uma rica biodiversidade, além de um relevo peculiar com rios, igarapés, cachoeiras, classificada como atração ecoturística. Dentre os componentes voltados ao ecoturismo, a diversidade de recursos aquáticos representa um forte atrativo para a prática da pesca esportiva. Nesse cenário, chama a atenção os ambientes impactados e que tiveram seu ecossistema 
modificado, como lagos artificiais resultantes da criação de hidrelétricas, os quais, depois do represamento da água e da formação de ilhas, se inseriram como produto desse seguimento.

Na Amazônia, a Usina Hidrelétrica de Tucuruí (UHE Tucuruí) adere à implantação do ecoturismo pela nova paisagem e pelo ambiente aquático que se formaram, propício à reprodução do Tucunaré (Cichla spp.), espécie muito procurada por praticantes da pesca esportiva. Construída no período entre 1974 e 1984, ainda no governo militar, a UHE Tucuruí representa a segunda maior barragem do país, ocupando parte do rio Tocantins, na região sudeste do Estado do Pará. Com uma dimensão de 100 quilômetros de comprimento e 18 quilômetros de largura, o lago compõe um total de 1.500 ilhas conforme levantamento de campo realizado em 2007. Sete municípios abrangem essa área do lago: Tucuruí, Breu Branco, Goianésia, Novo Repartimento, Nova Jacundá, Nova Ipixuna e Itupiranga (Figura 1).

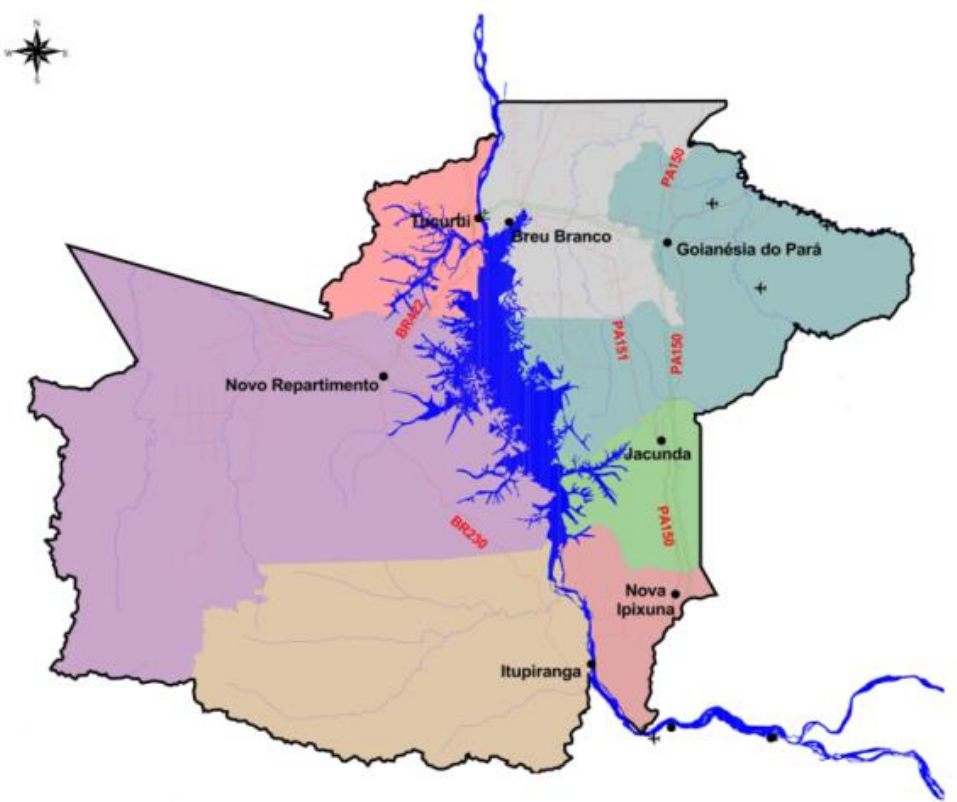

Figura 1: Área de abrangência do lago da UHE Tucuruí. Fonte: Eletronorte, 2009.

Figure 1: Coverage area of the lake UHE Tucuruí. Source: Eletronorte (2009).

Destaca-se que essa configuração municipal foi formada juntamente com a criação do lago. Antes, a sede do município de Jacundá se situava às margens do rio Tocantins, mas quando construída a barragem, foi remanejada para a PA-150 e a nova sede passou a se chamar Nova Jacundá. Breu Branco, Novo Repartimento e Goianésia foram criados em função do contingente migratório que se formou (ROCHA, 1999).

Até os dias atuais, a UHE Tucuruí é palco de conflitos e reivindicações por parte dos que foram atingidos pela transformação do rio em lago artificial. Esses conflitos vêm se acirrando juntamente com o fluxo migratório que se tornou perene. Em busca de melhores condições de vida, pessoas de todas as regiões do país, com destaque para as do nordeste, traçaram um caminho contínuo e chegam com diferentes práticas, interesses 
e perspectivas. Alocam-se nessa região fortemente modificada, dado o ineditismo da ação governamental na criação de lago artificial na Amazônia.

Costumes locais se aliam a novas práticas cotidianas, tanto no trato com a natureza quanto na reordenação do espaço e na interação com o ambiente aquático, principalmente na captura de peixes. Com a formação do reservatório, a pesca passou a representar a principal atividade econômica e - lago se tornou um espaço de conflito entre pescadores artesanais, industriais e, atualmente entre praticantes da pesca esportiva. O pescador artesanal conflitua com os pescadores industriais que se utilizam de equipamentos com grande capacidade de captura. Quanto à pesca esportiva, se dá porque o peixe capturado trata-se do tucunaré (Cichla spp.) que tem alto valor econômico local.

O presente artigo se estrutura em três sessões. A primeira apresenta a concepção de pescador enquanto população tradicional, assim como a relação que estabelece com a natureza. Esta descrição se faz necessária a fim de pontuar a distinção entre a pesca artesanal e a pesca esportiva amparada na política de ecoturismo bem como o enfrentamento diante da atual escassez do pescado, enfatizando a pesca artesanal e a pesca esportiva. A segunda sessão discorre sobre o ambiente aquático e de que forma a memória coletiva possibilitou o desempenho da atividade pesqueira num ecossistema fortemente alterado, permitindo a inserção de diferentes atores e de práticas pesqueiras (NORA, 1993). A terceira sessão apresenta o cenário atual da pesca no lago, enfocando a pesca esportiva a partir da concepção do desenvolvimento sustentável na qual se ampara a política de ecoturismo.

Como aporte metodológico, utiliza-se a base de dados constituída a partir de um amplo levantamento junto aos municípios no lago destacando o ecoturismo bem como observação direta nos locais de acesso à prática esportiva e à pesca artesanal.

\section{Pescador enquanto população tradicional e o enfrentamento de novas relações socioambientais.}

$\mathrm{Na}$ década de 1980, as ciências sociais passam a integrar a problemática ambiental, atuando principalmente no estudo das culturas, enfatizando a forma com a qual populações humanas se relacionam com os ambientes naturais, concebendo o homem como parte deste habitat. $\mathrm{Na}$ inserção a esta área do conhecimento, toma como objeto o estudo das populações tradicionais, considerando categorias como a de pertencimento, defendida por Little (2002). Outras, como a dependência com a natureza, o conhecimento aprofundado de seus ciclos, domínio do território para o exercício de todas as atividades culturais, sociais, econômicas e ambientais são arroladas por Diegues (2000) e Souza (1988). Para estes autores, o ambiente e a sociedade devem ser compreendidos na sua totalidade.

A pesca enquanto subsistência representa uma das atividades que integram a definição do conceito de povos tradicionais ${ }^{3}$ por relacionar 0 homem à natureza, no domínio e na interação dos ciclos, das espécies locais, dos saberes desenvolvidos na relação de acesso e uso, repassados 
de forma geracional ou adquiridos por meio da memória coletiva (LIMA, 2001). Antônio Cândido, em sua obra Os parceiros do rio bonito, detalha o cotidiano do caipira e, ao descrever os seus afazeres, demonstra a intensa relação destes com a natureza. Mostra como a forma de organização se adéqua às condições ambientais, o que prova como populações tradicionais vinculam-se fortemente ao ambiente.

Leitão (1997) faz um levantamento de forma linear das ações governamentais que culminaram no processo de criação de vários órgãos no Brasil, como a Superintendência de Desenvolvimento da Pesca, Instituto Brasileiro de Meio Ambiente e Recursos Renováveis, Grupo Executivo do Setor Pesqueiro, dentre outros, assim como os desdobramentos para as populações pesqueiras artesanais. Evidencia a incompatibilidade do modelo à realidade local, completamente deslocado da empiria, de sorte que "o pescador mesmo", assim descrito pela autora, como aquele que tem na sua identidade a pesca como modo de vida, não está inserido no modelo implantado pelo poder público, que contempla exclusivamente a pesca industrial, voltada, principalmente, para o mercado internacional.

$\mathrm{O}$ incentivo à aquisição de tecnologias também pode ser visualizado como algo que contribui para a exclusão do pescador artesanal. A pesca industrial, dotada de equipamentos de captura de alta produção e da capacidade de mobilidade por meio de grandes barcos, permite ao pescador industrial percorrer diversas regiões em busca do pescado, sem qualquer comprometimento com a sustentabilidade dos estoques pesqueiros, pois, à medida que ocorre o esgotamento em determinado lugar, procura outro para explorar, semelhante à pesca esportiva, exercida por turista, pessoa alheia à realidade local. Procura os locais mais propícios, e, quando eles se esgotam, parte para outro.

A pesca teve significativo aumento na produção, principalmente aquela voltada para o mercado internacional. Destaca-se, aqui, a produção de pesca em águas interiores, que alcançou a maior taxa crescente nas décadas de 1950 a 1990, superando a pesca de águas marinhas (FAO, 2000). Na produção do pescado de água doce, o Brasil ocupa o décimo lugar. Já a pesca esportiva é medida pelo quantitativo de turistas e pelo montante financeiro arrecadado, se enquadrando como atividade do turismo, obtendo também considerável crescimento.

Entretanto, há tendência de redução do pescado, em função da limitação dos sistemas aquáticos e do aumento do consumo decorrente do crescimento populacional. Segundo o relatório da FAO (2000; 2009), o aumento da produção vem gerando o esgotamento dos recursos pesqueiros em todo o mundo. A capacidade de suporte dos ambientes aquáticos aponta para o esgotamento dos recursos pesqueiros frente ao acelerado processo de degradação causado por um modelo que não considera o tempo da natureza e da reprodução dos organismos aquáticos nos processos de resiliência. Destaca-se que a pesca esportiva se dá pela fartura de uma determinada espécie. Não se efetiva na escassez, pois o turista o faz por diversão e não por subsistência, ao contrário do pescador artesanal.

Contudo, o pequeno pescador, o artesanal, tem sua produtividade limitada, não somente pela restrição do acesso à tecnologia, como barcos, 
grandes redes, financiamentos, embora isso não se traduza em desejo, por exercer uma baixa relação com o mercado. Geralmente, a área explorada é de fácil mobilidade, não exigindo grandes equipamentos, como embarcações. Todavia, como garantia de sobrevivência, reconhece a importância da conservação do ambiente pesqueiro para sua reprodução, outra lógica, nem sempre a do mercado, norteia o acesso e o uso dos recursos naturais (LEITÃO, 1997; FURTADO et al., 1993; MANESCHY, 1994).

O recorte sobre a pesca esportiva ganha robustez quando se trata da região amazônica. Marcada pela presença de rios, lagos, igarapés e igapós, - ciclo das águas forma sazonalidades específicas para captura de diferentes espécies de pescado, contribuindo, assim, para uma caracterização socioambiental peculiar que se perfila pelo uso de uma diversidade de apetrechos de pesca, o que envolve, segundo Barthem et al. (1997), uma grande complexidade, haja vista que as formas de organização social permeiam tais práticas (LEITÃO, 1997).

Os extensos rios de água doce e a abundante diversidade da vida aquática fazem com que a população tradicional tenha no rio sua principal fonte de subsistência. Ressalta-se, portanto, que, dentre as modalidades existentes, a pesca artesanal representa uma atividade de inteira ligação das populações tradicionais com o meio natural (MANESCHY, 1994). Concebe uma atividade que pode ser caracterizada pela sazonalidade e, portanto, pode-se aferir uma relação de dependência entre homem e natureza (ADOMILLI, 2012).

O ambiente aquático amazônico integra as populações humanas, sobretudo, as que margeiam os rios se agregam a conexão que se habituou chamar homem e natureza. Estabelecendo, desse modo, uma relação intrínseca, não sendo possível pensar todos os organismos vivos sem a presença desses moradores denominados ribeirinhos, que têm no rio não só o meio de locomoção, mas, a principal fonte de alimentação (CINTRA, 2004; ROCHA-TRINDADE, 2005; RUFINO, 2004).

Nem sempre a pesca representa a principal atividade dessas populações, em alguns contextos se destaca a agricultura, o extrativismo, por exemplo. Mesmo quando acentuada como atividade secundária, não deixa de ser menos importante para a sobrevivência humana, já que o peixe consiste na principal fonte proteica para a população amazônica (PEZZUTI, 2004). Em algumas situações, é praticada somente para o consumo ou, então, aos finais de semana. Isso implica dizer que a arte de pescar se constitui um saber de domínio de praticamente toda população tradicional da Amazônia (MALDONADO, 1985; NASCIMENTO, 1993).

A pesca de água doce tem se destacado como a mais ameaçada. Welcomme (1999) menciona a referida condição ao considerar a complexidade que envolve esta atividade, sobretudo, pela diversidade de apetrechos que são utilizados e pelas relações sociais que se estabelecem. Barthem et al. (1997) recomendam, nestes casos, o uso de estratégias de manejo que sejam adequadas do ponto de vista ecológico, considerando sempre as características de cada espécie. 
A pesca representa um recurso de livre acesso e, assim, fadado ao esgotamento, de acordo com a teoria de Hardin, quando aponta 0 desequilíbrio norteado pelo interesse individual ${ }^{4}$. Embora, Ostrom (1990) conteste essa predição de tragédia. Segundo ela, as populações tradicionais têm capacidade de gerir por meio da governança os bens comuns dentro de uma lógica de sustentabilidade. Nesse sentido, práticas atuais, articuladas aos contextos de mudança que perfilam os reservatórios de UHE, e no caso deste artigo, o lago de Tucuruí merece um olhar mais acurado na busca de compreensão das transformações e dos novos movimentos que desenham os processos sociais vinculados à pesca.

A geração de energia hidroelétrica causa danos imensuráveis ao ambiente aquático. Ao realizar o barramento em parte de um rio, se aniquila o mesmo (SAVÉ FILHO, 1988), pois, quando se transforma rio em lago, se atinge diretamente a população humana ali residente como bem definido por Nóbrega (2011); Vainer (1990, 1996, 2001). Ainda, de acordo com Savé Filho $(1988,2005,2008,2010)$, um rio barrado não é mais um rio e, após a mudança imposta pelo barramento, o rio passa a existir somente na memória das pessoas, o registro do que era anteriormente.

A alusão aqui empregada se refere especificamente às transformações pelas quais passou o rio Tocantins com a implantação da UHE Tucuruí. Desde o início do processo de criação até os dias atuais, grandes alterações ocorreram no trecho do rio que foi transformado em lago artificial pelo represamento da água. Essas transformações se refletem na mudança dos ciclos da água do rio, gerando consequências na vida humana e na manutenção da biodiversidade aquática, conforme enfatiza Magalhães (2007).

Como já mencionado, os lagos artificiais têm se tornado um ambiente atrativo para a pesca esportiva. $O$ acesso aos recursos pesqueiros tem gerado conflitos com pescadores artesanais, pois muitas ilhas onde estão localizadas as pousadas que hospedam esses turistas se restringem à pesca esportiva. Desse modo, o pescador artesanal vai perdendo as áreas de pesca.

A partir dos rumores da construção da UHE Tucuruí, muitos moradores passaram a habitar os centros urbanos no seu entorno. À medida que não conseguiram se inserir no projeto, geralmente pela não qualificação de mão de obra, buscaram as margens da represa e encontraram na pesca um meio de sobrevivência. Aproximadamente 72 espécies de pescado são capturadas no lago, mas um total significativo também desapareceu com a formação do reservatório (RAVENA et al, 2009; CINTRA, 2004). Trata-se das espécies que se utilizavam da corrente de água de rio, tais como o pacu (Piaractus mesopotamicus), o filhote (Brachyplathystoma filamentosum), a dourada (Brachyplatystoma rousseauxii), espécies que depois do represamento da água desapareceram, como afirma um antigo morador:

Tempo bom era quando o rio enchia e vazava e a gente podia pegar os peixes de corredeira. Agora não tem mais como, ficou tudo parado, e o peixe da corredeira sumiu, como que ele ia viver nisso aí? É muito triste (J.P.C, 76 anos). 
A complexidade do ponto de vista das mudanças sofridas envolve a adaptação ao novo ambiente aquático para captura e identificação de novos pontos de pesca no interior do lago. Algumas questões demandam uma reflexão a posteriori e constituem, hoje, estratégias que requerem, antes, compreender o passado para criar novas práticas de captura dos recursos pesqueiros e construir outros saberes acerca das mudanças no ecossistema.

\title{
Novo ambiente aquático e uso da memória coletiva no enfrentamento as mudanças.
}

Ainda que o ambiente aquático pareça uniforme aos olhos de um indivíduo qualquer, para o pescador, possui divisórias, marcas, características distintas num mesmo rio, lago ou igarapé. Área definida como mais rasa, mais funda, água mais parada, mais corrente ou sombreada pelas árvores representam diferentes formas de se perceber, classificar e lidar com o ambiente aquático. Furtado (2004), ao discorrer sobre a complexidade que envolve a pesca, enfoca a importância do saber nativo, enfatizando a necessidade deste conhecimento ser repassado para as demais gerações como garantia de sustentabilidade dos recursos pesqueiros. Abrange um saber que extrapola a classificação de pescador. Furtado discorre afirmando que:

\begin{abstract}
Quando se fala em sociedade pesqueira pensa-se nos grupos sociais que fazem da pesca, coleta e extrativismo marinhos e fluviais sua base de vida material e social. Dependendo da organização social, dos modos de produção e tecnologia adotados, estes podem ser classificados como "pescadores tradicionais' ou 'pescadores industriais", duas categorias de referência não nativas. Ambos, porém, são partes de um contexto sociocultural, econômico e político mais amplo e mais complexo, com o qual interagem e estão sujeitos às dinâmicas sociais intervenientes e, consequentemente, a níveis de maior ou menor complexidade (FURTADO, 2006 p.161).
\end{abstract}

Assim, cada lugar imprime na sua população as peculiaridades do ambiente. Por exemplo, quando um pescador que aprendeu a pescar em águas marítimas migra para rios de água doce, enfrenta dificuldades em saber a relação que se estabelece naquele lugar, na identificação e no costume das espécies, dentre outros. Todavia, terá conhecimento a partir da transmissão dos antigos moradores que repassam seus conhecimentos no contato com esses migrantes no transcorrer do tempo (FURTADO, 1997; DIEGUES, 2000, 2001).

Isso ocorre porque cada ambiente demanda um saber, do clima, dos ciclos da água, do período de reprodução de cada espécie e da arte de captura dos recursos pesqueiros (SOUZA, 2009). A dependência com a natureza, o conhecimento aprofundado dos ciclos da água, o domínio do território para o exercício de todas as suas atividades culturais, sociais, 
econômicas e ambientais são bastante explorados por Diegues (2000); Furtado (2004).

Desse modo, a pesca esportiva se utiliza de todo esse conhecimento para ser realizada, haja vista que o turista não conhece os pontos de pesca e nem o saber que envolve a captura. Esse pescador obtém o conhecimento da técnica no uso do equipamento apropriado como isca artificial, anzol e carretilha ou molinete.

Em trabalho de campo junto aos moradores que viveram no rio Tocantins antes da UHE Tucuruí, foi possível levantar relatos (Quadro 1) que apresentam com bastante riqueza de detalhes como era o tempo anterior à construção da barragem e que hoje permite 0 desenvolvimento das atividades da pesca por todos no lago.

Quadro 1: Memória do rio Tocantins por antigos moradores.

Table 1: Tocantins river memory of former residents..

\begin{tabular}{|c|c|c|}
\hline Morador & Ambiente aquático & Recursos pesqueiros \\
\hline $\begin{array}{l}\text { P.P.(71 anos) } \\
\text { sexo masculino }\end{array}$ & $\begin{array}{l}\text { Tinham cachoeiras enormes, } \\
\text { mas se acabaram. Eu não } \\
\text { imaginava que barragem matava } \\
\text { até cachoeira. }\end{array}$ & $\begin{array}{l}\text { Era muito farto, tinha muito peixe. } \\
\text { A gente pescava pra comer e o } \\
\text { resto dava pro pessoal. Tinha } \\
\text { muito, tudo ali na beira do rio. }\end{array}$ \\
\hline $\begin{array}{l}\text { O.M.B. (61 anos) } \\
\text { sexo feminino }\end{array}$ & $\begin{array}{l}\text { Quando viajo e vejo um rio } \\
\text { correndo, me corta o coração. } \\
\text { Vivia na glória, nunca a gente se } \\
\text { preocupou com o que comer. }\end{array}$ & $\begin{array}{l}\text { Tinha muito peixe e só grande. } \\
\text { Tinha tucunaré de } 5 \text { quilos. Hoje, } \\
\text { vejo eles fazendo festa quando } \\
\text { encontram um de } 2 \text { quilos. }\end{array}$ \\
\hline $\begin{array}{l}\text { R.G.Q. (80 anos) } \\
\text { sexo feminino }\end{array}$ & $\begin{array}{l}\text { O rio, a água correndo é a coisa } \\
\text { mais linda, desce e sobe. Hoje é } \\
\text { triste de ver aquela água toda } \\
\text { parada, quente. }\end{array}$ & $\begin{array}{l}\text { Tinha muito peixe e só grande, o } \\
\text { tucunaré, então, era enorme. Eu } \\
\text { passava o dia pescando lá no } \\
\text { Jatobal, era só atravessar, } \\
\text { pescava de linha. Eu amava } \\
\text { demais fazer isso. }\end{array}$ \\
\hline $\begin{array}{l}\text { J.F.S. (76 anos) } \\
\text { sexo masculino }\end{array}$ & $\begin{array}{l}\text { Você já imaginou um rio que } \\
\text { tinha diamante no seu leito? E as } \\
\text { cachoeiras? Quem não conheceu } \\
\text { não faz ideia do que era o } \\
\text { Tocantins. Nossa, muito rico e } \\
\text { lindo, viu? }\end{array}$ & $\begin{array}{l}\text { O pessoal de fora diz que tem } \\
\text { muito peixe no lago, mas é porque } \\
\text { eles não conheceram o rio. Ave } \\
\text { Maria, não tem comparação. }\end{array}$ \\
\hline $\begin{array}{l}\text { J.A.C. (87 anos) } \\
\text { sexo masculino }\end{array}$ & $\begin{array}{l}\text { O lugar era rico demais. Tinha } \\
\text { diamante, castanha, tudo quanto } \\
\text { era caça, cada cachoeira, peixe, } \\
\text { então, nem se fala, era uma } \\
\text { imensidade. }\end{array}$ & $\begin{array}{l}\text { Tinha todo tipo de peixe. Hoje em } \\
\text { dia, muitos já sumiram. Eu } \\
\text { pescava só pra comer. Mas a hora } \\
\text { que eu quisesse tinha, e ainda } \\
\text { escolhia pescar o peixe que eu } \\
\text { tava com vontade de comer. }\end{array}$ \\
\hline
\end{tabular}

Fonte: Trabalho de campo, setembro, 2014.

Source: Fieldwork, september, 2014.

Nesse sentido, torna-se bastante pertinente a interpretação que Lima (2001) faz de Halbwachs (1990), de que a memória é um retrato do passado. É a memória coletiva que faz com que o imigrante se aproprie das formas de captura, das práticas, fazendo sempre uma fusão entre o que traz consigo e o que adquire com outros moradores.

O processo de adaptação para as pessoas que viveram no rio Tocantins antes da barragem se tornou difícil gerando de certo modo uma rejeição do presente. Mas essa memória do rio é repassada aos que 
chegam ao lago, essa memória se torna fundamental. $\mathrm{Na}$ fala de um imigrante entrevistado no lago, é possível compreender essa realidade:

\begin{abstract}
Quando cheguei aqui, tinha medo até de subir na terra, hoje não, conheço tudo. Eu aluguei uma barca e um rapaz que conhecia trabalhou comigo como guia. Aí quando chegou ali, ele falou: tem um canal aqui, tem um braço do Tocantins ali, tem o Jacundazão ali e, do outro lado, se você ficar aqui tem o braço do Bacuri, então o senhor tá localizado num lugar bom de pescar. Assim que aprendi tudo daqui (G.C.L. 54 anos, natural do Ceará).
\end{abstract}

Destaca-se que o conhecimento anterior sobre a localização dos rios e igarapés, hoje inundados, representa o curso dos rios e braços nos quais se constituem os principais pontos de pesca. O nome utilizado ainda é o dos rios e igarapés. Jacundazão era um importante afluente do rio Tocantins, por exemplo, e se referem a ele, mesmo estando tudo inundado, sem demarcação visível.

Como já descrito, a intervenção antrópica com vistas à geração de energia, dentre outros, origina grandes impactos no meio ambiente natural, alterando completamente o mesmo. Tais mudanças se refletem nas práticas sociais de grupos que têm nesse mesmo ambiente a garantia de sobrevivência (ALMEIDA, 1996). Atualmente, para navegar no lago, é preciso conhecer o curso do rio e, quem detém esse conhecimento são os moradores que viveram na região antes da criação do mesmo. Hoje, esses moradores repassam esse conhecimento para outras gerações.

Os práticos (moradores antigos que conhecem todo o curso do rio) transitam pelo lago como se o rio estivesse ali, na fala deles, no fundo, submerso. Referem-se ao nome dos igarapés, dos braços de rios e, quando se olha, não é possível enxergar nada além da imensidão do lago. Ao serem questionados, afirmam estar tudo no fundo (RAVENA-CAÑETE et al., 2010).

\title{
Cenário atual de restrição aos recursos pesqueiros e o contexto da pesca esportiva.
}

Na perspectiva desconectada da realidade local, a pesca esportiva se configura como atração ao estranho, devendo ser preservada pelo mesmo. O conceito de sustentabilidade, dentro dos moldes do ecoturismo, incentivou a parceria entre o Programa Nacional de Desenvolvimento da Pesca Amadora (PNDPA) ${ }^{5}$, Instituto Brasileiro de Turismo e Instituto Brasileiro de Meio Ambiente e Recursos Renováveis com cooperação do Programa das Nações Unidas (PNUD) no ano de 1998. Tal parceria foi impulsionada durante o "Seminário de Pesca Esportiva e Agricultura: Participação do Crescimento Social, Econômico e Turístico do Brasil”, na Federação das Indústrias do Estado de São Paulo, promovido pelo Comitê da Cadeia Produtiva da Pesca e da Agricultura e participação do Ministério do Turismo no ano de 2011. Teve como objetivo transformar a pesca em instrumento econômico, social e ambiental, buscando atrair pescadores de todo o Brasil 
e de outros países para a atividade da pesca, visando à conservação dos recursos naturais e o fortalecimento da cultura local.

A implementação desse programa é de responsabilidade do Ministério da Pesca e Aquicultura. O art. $3^{\circ}$ da Lei no 11.959, de 29 de junho de 2009 define a pesca esportiva como um seguimento do turismo ecológico com objetivo de promover o turismo sustentável. Atribuem-se duas classificações: embarcado e desembarcado, o primeiro são os que se utilizam de barco padrão onde 0 piloto precisa credenciar-se mediante 0 documento denominado Arrais; e o desembarcado que não utiliza barco. Essa modalidade de pesca também não pode ter fins comerciais, a captura se restringe a 10 quilos acrescidos de mais uma unidade para pesca em águas continentais. Quanto ao tamanho da espécie capturada deve medir no mínimo 35 centímetros de comprimento.

Na prática tem se utilizado o pesque e solte como reforço no discurso da sustentabilidade. Todavia, algumas recomendações precisam ser consideradas no sentido de garantir ou pelo menos potencializar a sobrevivência do peixe. Destacam-se aqui preocupações identificadas como de risco por estudiosos da área como (LOPES, 2009): Com relação ao respeito aos equipamentos de uso, os muito grandes ou pequenos podem causar ferimento e estresse ao peixe, deslocamento da mandíbula e cansaço extremo durante captura levando-o a morte por excesso de ácido lático ou mesmo exaustão.

Os cuidados quanto aos anzóis tanto no material quanto nos cuidados em caso em que o peixe engole, o tamanho de corte do nylon vai influenciar na sobrevivência do peixe. $O$ atrito pode retirar escamas e muco reduzindo assim a resistência do peixe ou mesmo trauma pelo uso inadequado do alicate no momento do embarque ou na retirada do anzol. $E$ ainda, constituem-se cuidados imprescindíveis: o tempo fora da água, à queda do peixe, contenção pelas brânquias (guelra), contato físico, o procedimento adequado para segurar o peixe, a técnica de soltura, o local de soltura, a profundidade da captura, dentre outras.

A maior crítica a essa política repousa justamente na relação com a comunidade local. Esta, uma vez inserida no serviço ecoturístico, deixará suas atividades tradicionais, alterando seu modo de vida, suas práticas, seu cotidiano (FIGUEIREDO, 1999). Isto porque, embora o visitante busque conhecer o seu cotidiano, sabe-se que estas populações têm suas atividades orientadas por uma sazonalidade que demanda um tempo completamente distinto do convencional. O movimento das águas, as fases da lua, a posição do sol, nem sempre coadunam com o planejamento e o acompanhamento por parte do turista que fica preso à infraestrutura de serviços, como período de permanência, horários de viagens, hábitos e horários alimentares, por exemplo.

De acordo com Coelho (1999), essa percepção retoma uma concepção antiga de ver e pensar a natureza de forma a reproduzir mitos, lendas e imagens sobre a Amazônia, distorcendo o entendimento sobre esta região por meio do ecoturismo ao remeter o praticante a ideia de rusticidade, não alcance da modernidade, o que representa um retrocesso. 
O entendimento da pesca esportiva como atividade de lazer e esporte vem estimulando a realização de eventos com torneios que promovem a visibilidade do ambiente. Esses eventos também são garantidos por lei que assegura a realização dos mesmos por meio de pessoa jurídica. Desse modo, a formação de uma associação de pescadores esportivos em parceria com os municípios tem se tornado praxe. O estado do Pará sancionou a Lei 6.167, de 07 de dezembro de 1998 e posteriormente o decreto 3.551 de 06 de julho de 1999 constituindo assim os instrumentos legais de legitimação da pesca esportiva.

No lago formado pela UHE de Tucuruí, a pesca esportiva representa a principal atividade do ecoturismo e se efetiva, como já mencionado, em função da quantidade de tucunaré (Cichla spp.) e da paisagem de ilhas que se formou. É praticada como lazer por pessoas de maior poder aquisitivo, o que a difere da pesca artesanal, que, por sua vez, é realizada como fonte de sustento.

Buscando fomentar a economia, os municípios de Tucuruí e Nova Jacundá passaram a desenvolver anualmente um torneio de pesca esportiva. Tais eventos têm sido apresentados como atividades de ecoturismo. Um grupo de pessoas realiza um torneio de pesca sob regras gestadas pelos organizadores, e as premiações envolvem quantias em dinheiro aos vencedores.

A pesca esportiva ocorre mais no entorno da barragem pela proximidade com a cidade de Tucuruí, principal acesso ao lago e onde as atividades de turismo se concentram. De acordo com Ravena et al. (2007) nessa área, as ilhas que se formaram com a inundação do reservatório adquiriram um alto valor imobiliário, influenciado pelo turismo. Isso ocorre, ainda, em outra parte do reservatório com acesso através da estrada para Nova Jacundá, outro município maior produtor de pescado dentro do lago. Vale ressaltar que não há um plano de uso para a pesca esportiva e que finda desconsiderando os preceitos de sustentabilidade pela dificuldade de monitoramento. Embora o lago de Tucuruí se destaque e componha o roteiro da pesca esportiva não está contemplado no plano do PROECOTUR Amazônia, demandado para a Amazônia legal e que elegeu três áreas no Pará, excluindo o lago.

Entretanto, a intensificação da atividade, somada à falta de fiscalização, tem levado a uma acelerada diminuição do pescado (CINTRA et al., 2013), o que vem inviabilizando também a pesca esportiva, haja vista que a motivação se dá em função da abundância, do tamanho, logo, pela facilidade na captura.

Por outro lado, a atração para a prática de pesca esportiva no lago ocorre em função do novo ecossistema criado, propício à presença do tucunaré, considerado um peixe agressivo para captura, proporcionando maior estímulo de aventura ao praticante. A Figura 2 apresenta ambiente e espécie. 

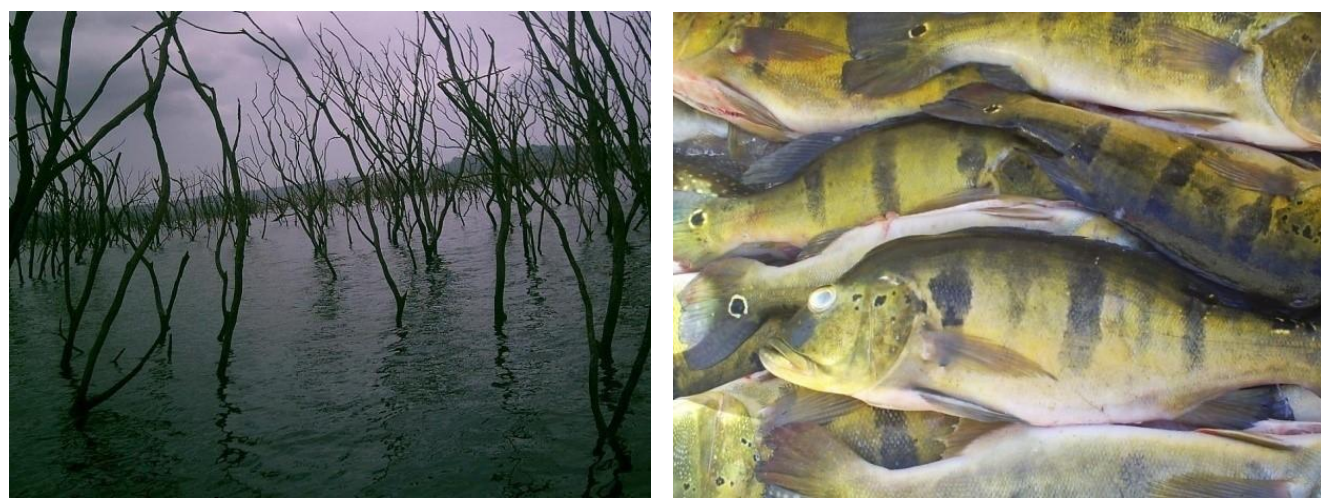

Figura 2: Área inundada, com árvores mortas chamadas de Paliteiro, é onde se captura o Tucunaré (à direita). Fonte: Trabalho de campo, 2014.

Figure 2: Flooded area with dead trees matchstick calls, is where you catch the Peacock Bass (right). Source: Fieldwork, 2014.

O tucunaré representa também o peixe de maior valor comercial. Como a produção é mais lenta pelo fato de ser pescado com anzol, o pescador artesanal é quem mais realiza essa pesca, diferentemente do pescador industrial, que se utiliza de grandes redes para captura de maior quantidade (CASTRO; McGRATH, 2001).

A participação dos pescadores artesanais do lago é necessária para o desempenho da pesca esportiva. Embora o pescador esportivo tenha o conhecimento das técnicas de captura, o pescador artesanal é conhecedor da geografia local e dos ambientes pesqueiros, ou seja, conhece os melhores lugares para pescar. Auxiliam também na informação quanto aos hábitos alimentares dos peixes para definição na escolha da isca e, principalmente, dos pontos de pesca.

Do ponto de vista do ambiente, foram levantados locais específicos para a captura do tucunaré: assento ou coito que são segundo os pescadores os locais onde ficam parados para se alimentar e se reproduzir, situam-se na ponta das ilhas também conhecido como sequeiro por ser uma área rasa. Existe ainda, a grota e ressaca que são as bocas de igarapés e em meio aos paliteiros (árvores mortas pela inundação).

Foram identificadas quatro técnicas na pesca que são: a de espera, a andada, a de assento e a de mergulho, esta última é proibida e considerada muito prejudicial por capturar o tucunaré durante reprodução, e que se trata de uma espécie que não há período de defeso. Quando ocorre para outras espécies, se acirra para a do tucunaré, haja vista que fica permitida somente a pesca com anzol, arte utilizada na pescar do tucunaré.

Considerando que o tucunaré é o principal produto da pesca esportiva, se constata um forte interesse por essa espécie e, consequentemente, a redução tanto no tamanho quanto no quantitativo desse pescado. De acordo com a avaliação técnica constante no relatório final do estudo de caso sobre a UHE Tucuruí, considerou-se o seguinte sobre o tucunaré: 
A queda nos desembarques de tucunarés pode ser reflexo do final de um ciclo de abundância de espécies forrageiras, presas naturais dos tucunarés que teriam aumentado suas populações no período inicial de pós-enchimento. Por outro lado, a pesca intensiva e seletiva do tucunaré pode ter contribuído para a queda da produção, pela ocorrência da sobrepesca; informações sobre esforço de pesca no reservatório poderão ajudar a elucidar as razões do declínio da pesca desta espécie (Relatório UHE Tucuruí, 2000, p.77).

Em trabalho de campo, se constatou a falta de monitoramento para a pesca esportiva. Os pescadores chegam em condução própria às comunidades que ficam às margens do lago, geralmente em dois, procuram um pescador artesanal para lhes acompanhar na aventura que dura de dois a cinco dias de permanência.

O pescador artesanal é quem vai levá-los aos pontos de pesca, uma espécie de guia. O pescador esportivo não passa por nenhuma fiscalização, embora deva estar credenciado por meio de licença, com permissão e autorização de competência do Ministério da Pesca e Aquicultura, Estados e Municípios. O recurso financeiro que deixa no município se restringe ao aluguel da rabeta e à diária do morador local, já que chega em condução própria e traz suas principais despesas (equipamentos de pesca, acessórios e alguns alimentos), tem o hábito de consumir o peixe junto com o moradorguia (pescador artesanal).

Moradores relatam que muitos chegam na condição de pescador esportivo e pegam um volume superior ao permitido e levam consigo. Não há enfrentamento com estes pescadores-guias pela pouca frequência e pelo grau de amizade que procuram estabelecer com o morador. Quando retornam ao lago, se comportam como revisitando um amigo local, sendo ignorados ou invisíveis aos gestores locais.

A pesca esportiva que se registra no lago é a promovida por meio de torneios que dois municípios realizam. Tucuruí promove há seis anos o TORTUC (Torneio de Tucuruí). O mais antigo se refere ao TORJAC (Torneio de Jacundá), há nove anos sendo realizado. Ambos são desenvolvidos através da associação de pescadores esportivos.

Cada associação elabora os regulamentos em consonância com a legislação vigente. Todos os participantes devem possuir a licença que, antes, era de responsabilidade do IBAMA e agora passou para o Ministério da Pesca e Aquicultura. A prática da pesca deve ser a de anzol e isca artificial, sendo a isca natural permitida desde que autorizada legalmente.

Sabe-se que na prática não ocorre nenhuma fiscalização e finda contribuindo para o esgotamento dos recursos pesqueiros, o que deveria ser um instrumento de conservação se transforma em mais uma oportunidade de exploração. 


\section{Considerações Finais}

Pensar em conservação dos recursos naturais através do desenvolvimento sustentável, modelo que se ampara nas políticas de ecoturismo e de pesca esportiva na UHE Tucuruí, parece um paradoxo. Isto porque o lago artificial resulta de um forte impacto no ecossistema, que passou de rio para lago.

Buscando mitigar os conflitos que se acirram no acesso e uso dos recursos aquáticos, o poder público tem incentivado o ecoturismo por meio da pesca esportiva. Embora disponha de toda uma legislação que discorra sobre a execução dessa atividade, na prática a mesma não é aplicada. Essa situação finda gerando uma série de fatores, a priori, prejudiciais ao contexto local. Até porque o referido incentivo não se efetiva por meio de fiscalização e monitoramento da atividade. E ainda, não dispõe de infraestrutura de serviços 0 que dificulta a prática considerando as dificuldades na acessibilidade ao lago.

O pescador esportivo, por não conhecer os pontos de pesca e mesmo a mobilidade no lago, contrata o serviço de um pescador artesanal que possua condução (rabeta) e com isso introduz este pescador em outra atividade à medida que ele deixa de pescar para guiar o pescador esportivo. O principal motivo que induz esta prática se dá em função da redução do pescado. Para o pescador esportivo, a busca está mais longe e mais dispersa e assim se procura quem sabe levá-lo aos pontos. O pescador artesanal, por seu turno, diminui as atividades da pesca artesanal, reduzindo o tempo de captura, pois prefere garantir a prestação de serviço junto à pesca esportiva.

Este cenário de escassez do pescado vem intensificando, especialmente do tucunaré que não possui defeso, e quando ocorre o defeso para outras espécies capturadas com redes, fica permitido somente a de anzol, utilizado para o tucunaré. Assim, a pesca esportiva também vem sendo ameaçada, haja vista que ela se dá em contextos de abundância, onde tem bastante peixe e de tamanho grande.

\section{Referências bibliográficas}

ADOMILLI, G. Territorialidade e conflito na pesca embarcada: um estudo de caso sobre os pescadores de São José do Norte - RS e suas analogias sobre animais marinhos. In: ADOMILLI, G; et al (Org.). Povos e Coletivos Pesqueiros: estudos etnográficos e perspectivas socioantropológicas sobre 0 trabalhar e o viver. 01 ed. Rio Grande: Editora FURG, 2012, v. 01, p. 15-42.

ALMEIDA, A.W.B. Refugiados do desenvolvimento: os deslocamentos compulsórios de índios e camponeses e a ideologia da modernização. Travessia - Revista do Migrante, ano XX, n. 25, 1996.

BARTHEM, R.B; et al. A pesca na Amazônia: problemas e perspectivas para o seu manejo. In: VALADARES-PÁDUA, C.; BODMER, R.E. Manejo e Conservação da Vida Silvestre no Brasil. MCT-CNPq, Sociedade Civil Mamirauá, 1997, p.173-184. 
CÂNDIDO, A. Os Parceiros do Rio Bonito. São Paulo: Livraria Duas Cidades, 1972.

CASTRO, F; McGRATH, D. O manejo comunitário de lagos na Amazônia. Parcerias Estratégicas - número 12 - setembro 2001.

CASTRO, E. Tradição e Modernidade. A propósito de formas de trabalho na Amazônia. Novos Cadernos NAEA, Belém, v. 2, n. 1, dez. 1999.

CINTRA, I.H.A; et al. A pesca na área de influência da Usina Hidrelétrica de Tucuruí - Estado do Pará. Boletim Técnico-Científico do CEPNOR, Belém, v. 4, n.1, p. 77-88, 2004.

CINTRA, I.H.A; et al. A pesca no Reservatório da Usina Hidrelétrica de Tucuruí, Amazônia, Brasil. Actapesca 1(1): 57-78, 2013.

COELHO, M.C.N. Reflexões sobre ecoturismo na Amazônia. In: O Ecoturismo e a questão ambiental na Amazônia. UFPA/NAEA: Belém, 1999.

COSTA, N.M.C.; NEIMAN, Z.; COSTA, V.C. (org.). Pelas Trilhas do Ecoturismo. Editora: RIMA 2008.

DIEGUES, A.C. Conceitos e definições. In: Saberes tradicionais e biodiversidade no Brasil. Brasília, Ministério do Meio Ambiente, 2001.

DIEGUES, A.C. (Org.) Etnoconservação: novos rumos para a proteção da natureza nos trópicos. São Paulo: Hucitec, 2000.

FAO. El estado mundial de la pesca y laacuicultura. Rome: FAO, 2009.196 p.

FAO. World Review of Fisheries and Aquaculture. FAO Fisheries Series. 2000.

FIGUEIREDO, S.L. O Ecoturismo e a questão ambiental na Amazônia. Belém: UFPA/NAEA, 1999.

FURTADO, L.G. Origens pluriétnicas no cotidiano da pesca na Amazônia: contribuições para projeto de estudo pluridisciplinar. Bol. Mus. Para. Emílio Goeldi. Ciências Humanas, Belém, v. 1, n. 2, p. 159-172, maio-ago, 2006.

FURTADO, L.G. Dinâmicas sociais e conflitos da pesca na Amazônia. In: Conflitos Ambientais do Brasil. ACSELRAD, H. (org.) Relume DCumara. Fundação Heinrich Böll. Rio de Janeiro, 2004 pp. 57-71.

FURTADO, L.G. Problemas ambientais e pesca tradicional na qualidade de vida da Amazônia. In: FURTADO, L.G. Amazônia: desenvolvimento, sociodiversidade e qualidade de vida. (Org.). Belém: UFPA / NUMA, 1997 (Universidade e Meio Ambiente, $\mathrm{n}^{\circ}$ 9).

FURTADO, L.G.; LEITÃO, W; MELLO, A.F. Povos das águas: realidade e perspectivas na Amazônia. Belém: PR/MCT/CNPq, Museu Paraense Emílio Goeldi, 1993.

HALBWACHS, M. A memória coletiva. São Paulo: Biblioteca Vértice, 1990.

HARDIN, G. The Tragedy of the Commons. Science, 162: 1243-1248, 1968.

LEITÃO, W.M. O pescador mesmo: um estudo sobre o pescador e as políticas de desenvolvimento da pesca no Brasil. 1997. Dissertação (Mestrado em Antropologia), Universidade Federal do Pará/Centro de Filosofia e Ciências Humanas/ Depto. de Antropologia/Programa de Pós Graduação em Antropologia Social (mimeo). 
LITTLE, P. Territórios sociais e povos tradicionais no Brasil: por uma antropologia da territorialidade. Série Antropologia, Brasília, n. 322, p. 1-32, 2002.

LIMA, D.M.; ALENCAR, E.F. A lembrança da Historia: memória social, ambiente e identidade na várzea do Médio Solimões. Lusotopie, 2001: 27-48.

LOPES, K.S. Plano de Uso para a Pesca Esportiva da Reserva de Desenvolvimento Sustentável Uatumã. IDESAN e CEUC, Amazonas, 2009.

MAGALHÃES, S. Lamento e Dor. Uma análise sócio-antropológica do deslocamento compulsório provocado pela construção de barragens. Tese de Doutorado. Programa de Pós-Graduação em Ciências Sociais. Universidade Federal do Pará/Université de Paris, 2007. Tese de Doutorado.

MALDONADO, S. Eu sou o dono desta canoa: reflexões sobre a antropologia da pesca. Cadernos Paraibanos de Antropologia, UFPB, João Pessoa, PB, N. 01, 1985. p. 43-55.

MANESCHY, C. Ajuruteua. Uma comunidade pesqueira ameaçada. Dissertação de Mestrado, UFPa. Belém, 1994.

MINISTÉRIO DO TURISMO. Ecoturismo: orientações básicas. Secretaria Nacional de Políticas de Turismo, Departamento de Estruturação, Articulação e Ordenamento Turístico, Coordenação Geral de Segmentação. 2. ed. - Brasília: Ministério do Turismo, 2010.

NASCIMENTO, Ivete. Homens e peixes: o tempo na pesca artesanal. Dissertação de mestrado. UFPA, 1993.

NÓBREGA, R.S. Os atingidos por barragens: refugiados de uma guerra desconhecida. Revista Interdisciplinar da Mobilidade Humana. Brasília, Ano XIX, № 36, p. 125-143, jan./jun. 2011.

NORA, P. Entre Memória e História: a problemática dos lugares. In: Projeto História. São Paulo: PUC, n. 10, pp. 07-28, dez de 1993.

OSTROM, E. Governing the Commons: the evolution of institutions for collective action, Indiana University, University Press, Cambridge, 1990.

PEZZUTI, J.C.B. Tabus alimentares. In: BEGOSSI, A. (Org.). Ecologia de Pescadores da Mata Atlântica e da Amazônia. Rio de Janeiro: Hucitec, 2004. v. 1

RAVENA, N.; RAVENA-CAÑETE, V.; SOUZA, C.L. Ainda Impactando: As Dinâmicas atuais de ocupação do entorno da represa de Tucuruí. Anais do I Encuentro Latinoamericano de Ciencias Sociales y Represas, 2007, Salvador.

RAVENA, N.; RAVENA-CAÑETE, V.; SOUZA, C.L. Lições não Aprendidas: Hidrelétricas, Impactos Ambientais e Política de Recursos Hídricos. Papers do NAEA (UFPA), v. 10, p. 1-17, 2009.

RAVENA, N.; RAVENA-CAÑETE, V.; SOUZA, C.L. Práticas, saberes e conflito em cenário de escassez de recursos naturais: o lago Tucuruí 30 anos depois. Anais do III Encontro Latinoamericano Ciências Sociais e Barragens, Belém, 2010a.

RAVENA, N.; RAVENA-CAÑETE, V.; SOUZA, C.L. Efeitos nefastos: Qualidade de Vida e Compensação Financeira em Área de Barragem. Anais do III Encontro Latinoamericano Ciências Sociais e Barragens, 2010, Belém. 
ROCHA-TRINDADE, M.B.; SOUZA CAMPOS, M.C. História, memória e imagens nas migrações: Abordagens metodológicas. CELTA Editora, Oeira, 2005. Portugal.

ROCHA, G.M. A construção da usina hidrelétrica e a redivisão político territorial na área de Tucuruí. Tese de Doutorado. São Paulo: USP, 1999.

RUFINO, M.L. A pesca e os recursos pesqueiros na Amazônia brasileira. Manaus: IBAMA/PROVÁRZEA, 2004.

SEVÁ FILHO, O. Obras na Volta Grande do Xingu - Um Trauma Histórico Provável? In: SANTOS, L.A; ANDRADE, L.M. (Orgs.). As hidrelétricas do Xingu e os povos indígenas. São Paulo: Comissão Pró-Índio de São Paulo, 1988.

SEVÁ FILHO, O. Conhecimento crítico das mega-hidrelétricas: para avaliar de outro modo alterações naturais, transformações sociais e a destruição dos monumentos fluviais. In: SEVÁ, O. (Org.). Tenotã-mõ: alertas sobre as consequências dos projetos hidrelétricos no rio Xingu. São Paulo: International Rivers Network, 2005.

SEVÁ FILHO, O. Estranhas catedrais. Notas sobre o capital hidrelétrico, a natureza e a sociedade. Ciência e Cultura, v. 60, n. 3, p.44-50. São Paulo, 2008.

SEVÁ FILHO, O. Problemas intrínsecos e graves da expansão mineral, metalúrgica, petrolífera e hidrelétrica nas Amazônias. In: ZHOURI, A; LASCHESFKI, K. (Orgs.). Desenvolvimento e Conflitos Ambientais. Belo Horizonte: Editora UFMG, 2010.

SOUZA, A.M. Os Trabalhadores da Amazônia Paraense e as Grandes Barragens. In: SANTOS, L.A; ANDRADE, L.M. (Orgs.). As hidrelétricas do Xingu e os povos indígenas. São Paulo: Comissão Pró-Índio de São Paulo, 1988.

SOUZA, C.L. Amazônia, para além da discussão entre campo e cidade: o município de Tapauá/AM em foco. Belém, 2009, 112f. Dissertação (Mestrado em Desenvolvimento e Meio Ambiente Urbano) - Universidade da Amazônia.

VAINER, C; ARAUJO, F.G. Implantação de grandes hidrelétricas. Estratégias do setor elétrico; estratégias das populações atingidas. Travessia - Revista do Migrante, ano. II, n. 6, 1990.

VAINER, C. A violência como fator migratório: silêncios teóricos e evidências históricas. Travessia - Revista do Migrante, ano XX, n. 25, 1996.

VAINER, C. Deslocados, reassentados, clandestinos, exilados, refugiados, indocumentados. As novas categorias de uma sociologia dos deslocamentos compulsórios e das restrições migratórias. In: GARCIA CASTRO, M. (Org.). Migrações internacionais: contribuições para políticas. Brasília: CNPD, 2001.

WELCOMME, R.L. A review of a model for qualitative evaluation of exploitation levels in multi-species fisheries. Fisheries Management and Ecology, 6:1-19, 1999. 


\section{Notas:}

1 Este artigo é derivado de tese de doutoramento e obteve apoio financeiro da CAPES.

2 Ecoturismo aqui se orienta pela definição de que: o princípio fundamental do ecoturismo é o de promover a realização de atividades de lazer e contemplação da natureza atrelada a conservação e educação ambiental (COSTA; NEIMAN.; COSTA, 2008).

${ }^{3}$ O Decreto 6.040 de 13 de julho de 2006, no Art. $3^{\circ}$, assim os define: "grupos culturalmente diferenciados e que se reconhecem como tais, que possuem formas próprias de organização social, que ocupam e usam territórios e recursos naturais como condição para sua reprodução cultural, social, religiosa, ancestral e econômica, utilizando conhecimentos, inovações e práticas gerados e transmitidos pela tradição".

${ }^{4}$ A concepção de livre acesso aos recursos comuns, interpretado por Hardin (1968) permeia a lógica de acesso entre o uso individual e o coletivo. Segundo este autor, o livre acesso levaria a uma tragédia dos recursos comuns, haja vista que são limitados.

${ }^{5}$ A Política Nacional de Desenvolvimento Sustentável da Pesca e Aquicultura, instituída pela Lei 11.959 de 29 de junho de 2009 contempla também a Pesca Amadora. Considerando que nesta atividade o peixe não pode ser comercializado, busca-se fomentar a economia por meio da atividade turística sem desconsiderar a valoração e conservação da cultura local e dos recursos naturais.

Cleide Lima de Souza: Universidade Federal do Pará, Belém, PA, Brasil.

E-mail: cleidedesouza@yahoo.com.br

Link para o currículo Lattes: http://lattes.cnpq.br/9911982898285564

Voyner Ravena Cañete: Universidade Federal do Pará, Belém, PA, Brasil.

E-mail: ravenacanete@gmail.com

Link para o currículo Lattes: http://lattes.cnpq.br/9961199993740323

Data de submissão: 09 de janeiro de 2015

Data de recebimento de correções: 29 de outubro de 2015

Data do aceite: 29 de outubro de 2015

Avaliado anonimamente 